\title{
PC Modeling and Simulation of Car Suspension System
}

\author{
M. Prem Jeya Kumar ${ }^{1 *}$, K . Gopalakrishnan², V. Srinivasan ${ }^{3}$, \\ R. Anbazhagan ${ }^{4}$ and J. Sundeep Aanand ${ }^{5}$ \\ 'Professor, Department of Automobile Engineering, Bharath University, Chennai-73; \\ premjeyakumar.coe@bharathuniv.ac.in \\ 2Professor of Electronics, Department of Electronics, Bharath University, Chennai-73; gopikrishna2804@gmail.com \\ 3Professor, Department of Automobile Engineering, Bharath University, Chennai-73; srinivasan@v9669.yahoo.co.in \\ 4Professor, Department of Automobile Engineering, Bharath University, Chennai-73; anbu.mit@gmail.com \\ ${ }^{5}$ Professor, Department of Computer Science Engineering, Bharath University, \\ Chennai-73; sundeepssn@hotmail.com
}

\begin{abstract}
The car suspension system of this model contains two parts. The first part deals with the formulation of a mathematical model for a conventional full car passive suspension system. Typically, the mathematical modeling is done on the basis of mechanical network analysis. The second part deals with simulation of the mathematical model of the suspension system. Simulation is carried out using MATLAB. Program was carried out for MATLAB and the simulation results were obtained in the form of graphical plots.
\end{abstract}

Keywords: Passive Suspension Sprung Mass, Unsprung Mass, Dampers, Spring.

\section{Introduction}

The first step towards achieving a simulation for a passive suspension is to generate the basic equation of motions for the dynamic system. The seven basic degrees of freedom considered for derive the equation of motion are, four linear motion about each suspension, one linear motion about the mass at the centre of gravity, one angular displacement about the longitudinal axis known as 'Roll' [1-3].

The mathematical model of car is to identify the problems which occur in the suspension of the cars and SUV's. With the help of vehicle data's, the exact physical characteristics of that car can be obtained by simulating the mathematical model. For that MATLAB software is mainly used to simulate the car.

\section{*Corresponding author:}

M. Prem Jeya Kumar (premjeyakumar.coe@bharathuniv.ac.in)

\section{Mathematical Modeling Basics}

A mathematical model of a dynamic system is defined as a set of equations that represents dynamics of the system accurately or at least, fairly well. A mathematical model is not unique to a given mechanical system. A system may be represented in many different ways and therefore may have many mathematical models, depending on one's perspective.

The dynamics of a mechanical system can be described in terms of differential equations. Such differential equations may be obtained by using physical laws governing particular system, for example, Newton's laws are used in case of a mechanical system. Mathematical models may assume many different forms. Depending on the particular system and the particular circumstances, one mathematical 
model may be better suited than other models. Once a mathematical model of a system is obtained, various analytical and computer tools can be used for analysis and synthesis purposes.

\section{Full Car Model}

A full car model constitutes of four unsprung masses connected to a single sprung mass about the centre of gravity of the vehicle and four dashpot and spring arrangements used to connect the sprung mass with the unsprung masses. The schematic representations of the car model are given below $[4,5]$.

Apart from the four displacement measurements, full car model also takes into account one vertical displacement about the centre of gravity, pitching motion about the transverse axis and rolling motion about the longitudinal axis for modeling of the system.

The highlight of the full car mathematical model is that it can be used to include all type of motion like yaw, toe-in, toe-out, etc.

\section{Dynamics of Full Car Model}

Based on the full car model, the equations of motion for the full car model have been derived, using network analysis.
The linearized equations of motions of the full car model can be expressed as

$$
m_{f 1} \ddot{Z}_{u 1}=U_{p 1}+F_{r 1}
$$

$$
m_{f 2} . \ddot{Z}_{u 2}=U_{p 2}+F_{r 2}
$$

$$
m_{r 1} . \ddot{Z}_{u 3}=U_{p 3}+F_{r 3}
$$

$$
m_{r 2} \cdot \ddot{Z}_{u 4}=U_{p 4}+F_{r 4}
$$

$$
\begin{gathered}
m_{s} \ddot{Z}_{s}=F_{s}-U_{p 1}-U_{p 2}-U_{p 3}-U_{p 4} \\
\mathrm{I}_{\theta} . \ddot{Z}_{\theta}=\mathrm{T}_{\theta}+1_{f} U_{p 1}+1_{f} U_{p 2}-1_{r} U_{p 3}-1_{r} U_{p 4} \\
\mathrm{I}_{\Phi} \cdot \ddot{Z}_{\Phi}=\mathrm{T}_{\Phi}-t_{f} U_{p 1}+t_{f} U_{p 2}-t_{r} U_{p 3}+t_{r} U_{p 4}
\end{gathered}
$$

where, the passive suspension forces are given by

$$
\begin{gathered}
U_{p 1}=C_{f 1}\left(\dot{Z}_{u 1}+1_{f} \dot{Z}_{\theta}-t_{f} \dot{Z}_{\Phi}-\dot{Z}_{S}\right)+k_{f 1}\left(Z_{u 1}-Z_{s}\right) \\
U_{p 2}=C_{f 2}\left(\dot{Z}_{u 2}+1_{f} \dot{Z}_{\theta}+t_{f} \dot{Z}_{\Phi}-\dot{Z}_{S}\right)+k_{f 2}\left(Z_{u 2}-Z_{s}\right)
\end{gathered}
$$

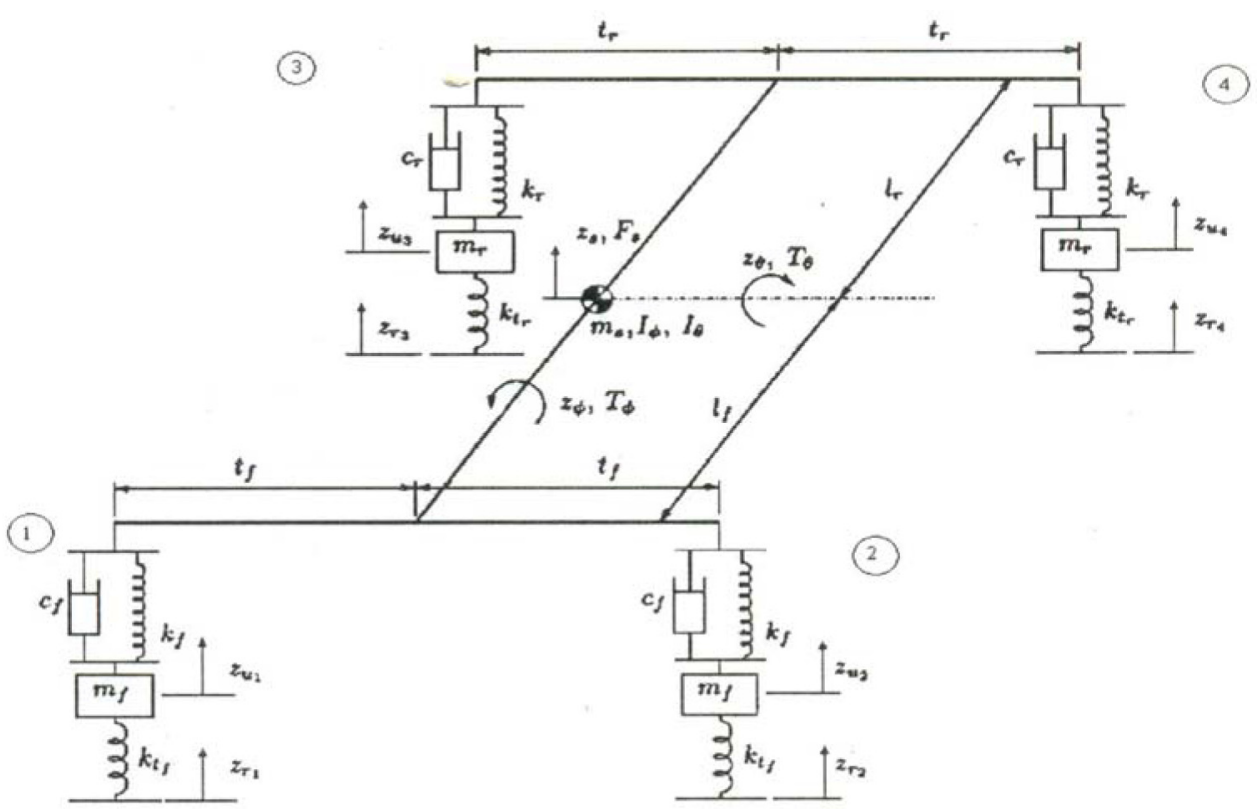

Figure 1. Full Car Model. 


$$
\begin{aligned}
& U_{p 3}=C_{r 1}\left(\dot{Z}_{u 3}-1_{r} \dot{Z}_{\theta}-t_{r} \dot{Z}_{\Phi}-\dot{Z}_{S}\right)+k_{r 1}\left(Z_{u 3}-Z_{s}\right) \\
& U_{p 4}=C_{r 2}\left(\dot{Z}_{u 4}-1_{r} \dot{Z}_{\theta}+t_{r} \dot{Z}_{\Phi}-\dot{Z}_{S}\right)+k_{r 2}\left(Z_{u 4}-Z_{s}\right)
\end{aligned}
$$

$$
\mathrm{k}_{\mathrm{tf}}=\mathrm{k}_{\mathrm{tr}}=250 \mathrm{kN} / \mathrm{m}
$$

\section{Simulation Results}

and the tyre forces are given by:

$$
\begin{aligned}
& F_{r 1}=k_{t f 1}\left(z_{r 1}-z_{u 1}\right) \\
& F_{r 2}=k_{t f 2}\left(z_{r 2}-z_{u 2}\right) \\
& F_{r 3}=k_{t f 3}\left(z_{r 3}-z_{u 3}\right) \\
& F_{r 4}=k_{t f 4}\left(z_{r 4}-z_{u 4}\right)
\end{aligned}
$$

\section{State Space Representation}

The linearized equations (1-7) are then converted into space form by comparing the coefficients of state vectors and input vectors. The state space model is given by

$$
\begin{aligned}
& \dot{X}=\mathrm{Ax}+\mathrm{Bu} \\
& \mathrm{Y}=\mathrm{Cx}+\mathrm{Du}
\end{aligned}
$$

where, A - state matrix

B - Input Matrix

C - Output Matrix

D - Direct transmission matrix

$\mathrm{X}$ - State vector

Y - Output Vector

Assuming state vector \& input vector to be,

$$
\begin{aligned}
& x=\left[\dot{Z}_{u 1} Z_{u 1} \dot{Z}_{u 2} Z_{u 2} \dot{Z}_{u 3} Z_{u 3} \dot{Z}_{u 4} Z_{u 4} \dot{Z}_{s} Z_{s} \dot{Z}_{\theta} Z_{\theta} \dot{Z}_{\Phi} Z_{\Phi}\right]^{T} \\
& u=\left[\begin{array}{llll}
z_{r 1} & z_{r 2} & z_{r 3} & z_{r 4}
\end{array}\right]^{T}
\end{aligned}
$$

The values of other matrices in the state space model were obtained.

Taking state space model into account, a Mat lab program were written to convert the matrices into a model. These models were used for running simulation by providing real constants value from a typical SUV. The parameters used are

$$
\begin{array}{lll}
\mathrm{m}_{\mathrm{s}}=1600 \mathrm{Kg} & \mathrm{I}_{\theta}=1000 \mathrm{~kg} \mathrm{~m}^{2} & \mathrm{I}_{\varphi}=450 \mathrm{~kg} \mathrm{~m}^{2} \\
\mathrm{t}_{\mathrm{f}}=\mathrm{t}_{\mathrm{r}}=0.75 \mathrm{~m} & \mathrm{l}_{\mathrm{f}}=1.15 \mathrm{~m} & \mathrm{l}_{\mathrm{r}}=1.35 \mathrm{~m} \\
\mathrm{~m}_{\mathrm{f}}=\mathrm{m}_{\mathrm{r}}=50 \mathrm{~kg} & \mathrm{k}_{\mathrm{f}}=\mathrm{k}_{\mathrm{r}}=20 \mathrm{kN} / \mathrm{m} & \mathrm{c}_{\mathrm{f}}=\mathrm{c}_{\mathrm{r}}=5 \mathrm{kN} / \mathrm{m}
\end{array}
$$
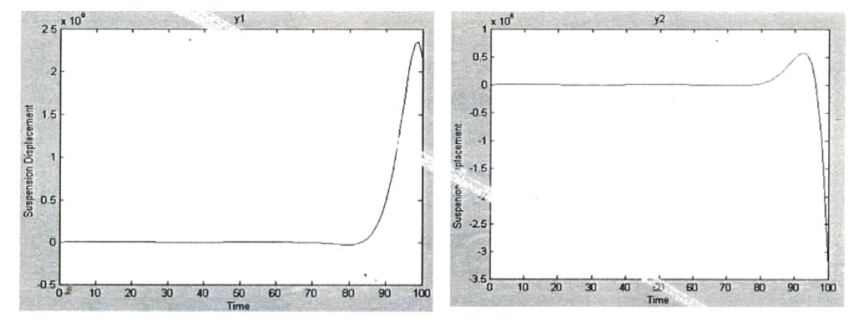

Figure 2. Passive suspension displacements at node 1 and node 2 respectively.

\section{Conclusion}

The dynamic equations of motion were derived, taking in to account the seven degrees of motion. These seven equations of motion form the mathematical model of the car. This model is further used for simulation by providing with real time parametric values of an SUV. The simulation results obtained depict the exact response characteristics of the full car model. For a positive road input at node 1 the suspension displacement turned out to be in positive direction, while a negative road input at node 2 depicted a similar output. The main application of this simulation would be in the problem identification of the suspension system in any car. The only modification that has to be made is to supply the parametric values of the particular model which is being investigated.

\section{Symbols and Abbreviation}

$m_{f 1,2}=$ unsprung mass at the front end

$m_{r 1,2}=$ unsprung mass at the rear end

$\mathrm{m}_{\mathrm{s}}=$ sprung mass at the centre of gravity of the vehicle

$\mathrm{I}_{\Phi}=$ moment of inertia about the sprung mass due to roll

$I_{\varphi}=$ moment of inertia about the sprung mass due to pitch

$\mathrm{M}=$ moment about the sprung mass

$\mathrm{C}_{\mathrm{f} 1,2}=$ damper rate at the front end

$\mathrm{C}_{\mathrm{r} 1,2}=$ damper rate at the rear end

$\mathrm{K}_{\mathrm{fl}, 2}=$ spring stiffness at the front end

$\mathrm{K}_{\mathrm{r} 1,2}=$ spring stiffness at the rear end

$\mathrm{k}_{\mathrm{t} t 1,2}=$ tyre stiffness at the front end

$\mathrm{k}_{\mathrm{tr} 1,2}=$ tyre stiffness at the rear end

$\mathrm{U}_{\mathrm{pl}-4}=$ passive suspension forces 
$\mathrm{U}_{\mathrm{cfl}, 2}=$ damper forces at the front end

$\mathrm{U}_{\mathrm{crl}, 2}=$ damper forces at the rear end

$\mathrm{U}_{\mathrm{kf1}, 2}=$ spring forces at the front end

$\mathrm{U}_{\mathrm{kr}, 2}=$ spring forces at the rear end

$\mathrm{U}_{\mathrm{mfl}, 2}=$ opposing forces due to unsprung mass at front end

$\mathrm{U}_{\mathrm{mrl}, 2}=$ opposing forces due to unsprung mass at rear end

$\mathrm{U}_{\mathrm{ms}}=$ opposing torque due to sprung mass at centre of gravity.

$\mathrm{T}_{\theta \mathrm{i}}=$ opposing torque due to pitch

$\mathrm{I}_{\Phi_{\mathrm{i}}}=$ opposing torque due to roll

$\mathrm{T}_{\theta}=$ torque due to pitch

$\mathrm{T}_{\varphi}=$ torque due to roll

$\mathrm{F}_{\mathrm{s}}=$ external load disturbances.

$\mathrm{F}_{\mathrm{r}}=$ force exerted on unsprung mass

$\mathrm{Z}_{\mathrm{r} 1-4}=$ tyre displacements

$\mathrm{Z}_{\mathrm{u} 1,2}=$ unsprung mass deflection at the front end

$Z_{\mathrm{u} 3,4}=$ unsprung mass deflection at the rear front

$Z_{s}=$ sprung mass deflection at the centre of gravity
$\mathrm{Z}_{\theta}=$ angular displacement due to pitch

$\mathrm{Z}_{\varphi}=$ angular displacement due to roll

\section{References}

1. Ogata K (2001). Modern control engineering, $3^{\text {rd }}$ Edn., Prentice-Hall of India.

2. Cebon D (1993). Interaction between heavy vehicles and roads, $39^{\text {th }}$ Buckendale Lecture, $1^{\text {st }}$ Edn., SAE Interenational.

3. Smith M C, and Wang F (2002). Controller parameterization for disturbance response decoupling: application to vehicle active suspension control, IEEE Transactions on Control Systems Technology, vol 10(3), 393-407.

4. Williams R A (1997). Automotive active suspensions, Part-1: basic principles, Proceedings of the Institution of Mechanical Engineers Conference, vol 211, No. 6, 415-426.

5. Crouse W H, and Anglin D L (2002). Automotive Mechanics, $9^{\text {th }}$ Edn., Tata McGraw Hill Edition. 